\title{
INISIASI PENDAMPINGAN PENDIDIKAN KECAKAPAN HIDUP MELALUI PROGRAM BELAJAR DAN BERKARYA SELAMA MASA PANDEMI COVID-19 DI NGORO MOJOKERTO
}

\author{
Della Kharisma Putri ${ }^{1}$, Yudha Nurdian ${ }^{2}$ \\ 1)Program Studi S1 Ilmu Keperawatan, Fakultas Keperawatan, Universitas Jember \\ 2)Universitas Jember \\ dellakharisma5@gmail.com,yudhanurdian78@gmail.com
}

\begin{abstract}
The Covid-19 pandemic has been going on since discovering the first case on March 2, 2020, in Indonesia. Implementing the "Study From Home" policy has generated a lot of controversy among the community. The lack of innovation in carrying out teaching and learning activities often creates anxiety. The number of tasks assigned to students resulted in various complaints, including; students become lazy to study, not disciplined in time, bored, and can even cause stress. The "Learning and Working" program is expected to be an alternative for children's learning during the Covid-19 pandemic and building life skills from an early age.
\end{abstract}

Keywords: Study From Home, Study, and Creation, Study Alternatif.

\begin{abstract}
Abstrak
Pandemi covid-19 sudah berlangsung sejak ditemukannya kasus pertama pada tanggal 2 Maret 2020 lalu di Indonesia. Diterapkannya kebijakan "Study From Home” banyak menuai kontroversi antar kalangan masyarakat. Kurang adanya inovasi dalam menjalankan kegiatan belajar mengajar seringkali menimbulkan keresahan. Banyaknya tugas yang diembankan pada siswa menghasilkan berbagai keluhan diantaranya; siswa menjadi malas belajar, tidak disiplin waktu, bosan, bahkan dapat menimbulkan stres. Melihat kondisi tersebut, program "Belajar dan Berkarya" diharapkan menjadi sebuah alternatif belajar anak di masa pandemi Covid-19 sekaligus membangun kecakapan hidup sejak dini.
\end{abstract}

Kata kunci: Study From Home, Belajar dan Berkarya, Alternatif Belajar. 
Della Kharisma Putri, dkk. Inisiasi Pendampingan Pendidikan Kecakapan Hidup...

\section{PENDAHULUAN}

Mojokerto merupakan salah satu kabupaten di provinsi Jawa Timur dengan menjunjung tinggi peradaban jawa peninggalan kerajaan Majapahit. Secara geografis kabupaten Mojokerto terletak antara 111 20 '13” s/d $111^{\circ} 40^{\prime} 47^{\prime \prime}$ Bujur Timur dan antara $7^{\circ} 18^{\prime} 35^{\circ}$ s/d $7^{\circ} 47^{\prime \prime}$ dengan 18 kecamatan, 299 desa dan 5 kelurahan. Salah satu desa di kabupaten Mojokerto yang menjadi sasaran KKN kelompok 41 yakni desa Jasem. Desa Jasem sebagian besar terdiri dari persawahan dengan luas wilayah 214,10 Ha. Desa Jasem terdiri dari enam dusun yakni Jasem, Donorejo, Jetak, Karanggayam, Jajar, Sambong yang dipimpin oleh seorang kepala desa.

Rata - rata pendidikan terakhir masyarakat desa Jasem adalah SLTA. Desa Jasem memiliki beberapa instansi pendidikan atau sekolah negeri pada jenjang TK, SD dan SMP serta beberapa sekolah swasta milik yayasan. Terdapat pula PAUD dan TK kelolaan desa dengan gedung berada dalam satu lokasi. Kegiatan pembelajaran disesuaikan berdasarkan kurikulum yang telah ditetapkan dari dinas pendidikan. Segala prestasi baik akademik maupun non akademik difasilitasi oleh pihak sekolah melalui berbagai kompetisi baik di luar maupun di dalam daerah. Instansi yang sering menjadi perhatian desa yakni PAUD \& TK serta satu sekolah negeri tingkat dasar yaitu SDN Jasem.

Sejak pemerintah menggagas kebijakan terkait protokol kesehatan selama masa pandemi covid-19, seluruh kegiatan yang mengharuskan adanya perkumpulan terpaksa dihentikan. Dampak dari penerapan protokol tersebut sangat dirasakan salah satunya dalam sektor pendidikan. Kegiatan belajar mengajar di sekolah dialihkan dengan belajar dari rumah yang sudah berjalan kurang lebih tiga bulan. Hal ini menyebabkan berbagai masalah yang dirasakan siswa dan orang tua terutama dalam tingkat pendidikan dasar seperti kebutuhan kuota internet, tidak terpantaunya kegiatan belajar, kurang efektifnya manajemen waktu, serta kurangnya pemahaman akan materi yang disampaikan oleh guru.

Pada pembelajaran jarak jauh sering menyebabkan fleksibilitas jadwal yang telah ditetapkan sehingga siswa terkadang meremehkan kegiatan pembelajaran yang harusnya tetap dilaksanakan secara profesional. Selain itu, masih terbatasnya sarana komunikasi modern dan kurangnya pengetahuan terkait teknologi pada kalangan orang tua siswa membuat guru tidak mempertimbangkan penggunaan model pembelajaran tatap muka secara online dengan media zoom atau google meet dalam strategi pembelajarannya. Sehingga dalam hal ini guru hanya memberikan tugas yang dikirim via WhatsApp Group (WAG).

Pemberian tugas via WAG pada siswa SD menimbulkan masalah baru dalam proses belajar mengajar sehingga dianggap kurang efektif. Tidak adanya interaksi antara guru dan murid menyebabkannya kesulitan dalam hal pemahaman materi dan penurunan motivasi belajar pada anak. Dalam hal ini bukan hanya permasalahan akademik yang dihadapi, namun kecakapan hidup menjadi hal lain yang perlu disoroti. Tidak adanya pemantauan secara langsung antara guru dan murid menjadikan kegiatan belajar mengajar sepenuhnya berada pada kendali orang tua. Orang tua dengan kesadaran yang rendah akan beresiko memberikan pengasuhan yang tidak tepat dalam proses belajar. Beberapa fenomena yang terjadi di desa Jasem terkait hal tersebut yaitu tidak adanya 
disiplin waktu dalam menjalankan aktivitas di rumah, semua tugas hanya dikerjakan oleh orang tua agar cepat selesai karena anak malas belajar, pola belajar yang berubah, dsb. Pengasuhan yang salah tersebut akan berdampak pada karakter anak sehingga anak rendah dalam aspek tanggung jawab, kejujuran, disiplin, dll.

Dalam menghadapi resiko penurunan pendidikan kecakapan hidup tersebut, mahasiswa KKN 41 Universitas Jember membuat suatu inovasi pembelajaran. Model pembelajaran ini bersifat non-internet guna membantu siswa dan orang tua dalam membentuk karakter yang baik selama masa pandemik covid-19 berlangsung melalui "Wall-Art Schedule Magazine”. Program ini dirancang sesuai dengan petunjuk dalam buku pedoman KKN tematik Back To Village Universitas Jember tahun 2020.

\section{METODE PELAKSANAAN}

Pengabdian kepada masyarakat ini dilaksanakan di Desa Jasem (Rt. 07 Rw. 05) Kecamatan Ngoro, Kabupaten Mojokerto. Pemilihan lokasi ini selain karena merupakan lingkungan terdekat dengan tempat tinggal peneliti namun juga merupakan lingkungan dengan jumlah anak - anak usia sekolah dasar yang cukup banyak. Metode pelaksanaan program ini meliputi lima tahapan yaitu survei awal, perencanaan, pembekalan, pelaksanaan dan evaluasi program. Seluruh pelaksanaan tahapan kegiatan ini tidak lepas dari pemantauan taat protokol covid-19 yang telah ditetapkan.

\section{Survei Awal}

Survei awal berisi kegiatan untuk mengamati permasalahan yang muncul akibat kebijakan sekolah dari rumah oleh akibat covid-19 di lingkungan sasaran. Selain itu peneliti juga melakukan perizinan kepada kepala desa dan orang tua siswa selaku sasaran terkait akan diadakannya program tersebut.

\section{Perencanaan}

Perencanaan program dibahas bersama kepala desa dan sasaran ketika permasalahan telah dirumuskan. Rancangan kegiatan yang akan dilakukan selama program berlangsung juga merupakan kesepakatan dan kesediaan bersama.

\section{Pembekalan}

Pembekalan merupakan kegiatan yang berisi pengenalan dan pelatihan dasar untuk siswa terkait isi konten yang akan dimuat dalam program utama (penyusunan wall-art).

\section{Pelaksanaan}

Pelaksanaan dari program wallart schedule magazine ini berupa penyusunan seluruh konten yang telah dilaksanakan saat pembekalan menjadi sebuah kaya wall-art bagi setiap individu (siswa).

\section{Evaluasi}

Evaluasi merupakan penilaian dari program yang diambil melalui respon siswa dan orang tua terkait perubahan, manfaat atau baik buruknya kondisi setelah program dilaksanakan.

\section{HASIL DAN PEMBAHASAN}

\section{Bernyanyi Bersama Untuk Memperkenalkan protokol covid-19}

Kegiatan ini bertujuan untuk memperkenalkan anak - anak tentang strategi pencegahan penularan covid-19 melalui pendekatan sebuah lagu sederhana. Peneliti menciptakan sebuah lagu tentang protokol covid-19 dengan irama "Balonku" yang sudah familiar di telinga anak - anak sehingga memudahkan untuk dihafalkan. Dengan begitu diharapkan anak selalu 
mengingat apa saja langkah proteksi yang harus dibiasakan selama masa pandemic ini berlangsung.

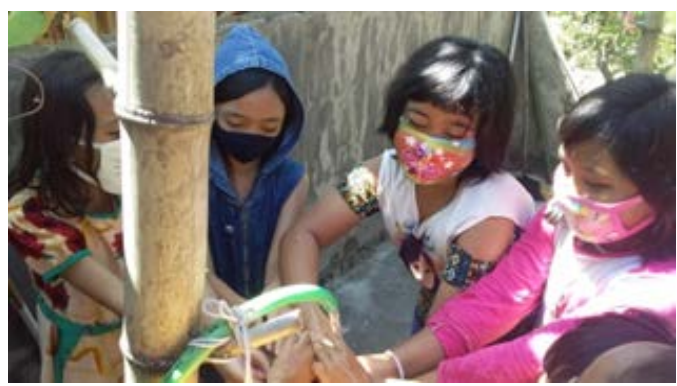

Gambar. 1 Kegiatan Mencuci Tangan

Syair lagu protokol Covid-19:

Sekarang musim corona

Sehatnya harus dijaga

Jaga jarak satu meter

Jangan lupa pakai masker

Yok ayok cuci tangan yok!

Lebih baik pakai sabun

Jangan berkerumunan

Semoga tak tertular

\section{Berkarya Dengan Teknologi Digital Sederhana}

Di era digitalisasi saat ini pendekatan teknologi sangan diperlukan dan diajarkan sejak dini. Selain karena kebutuhan konten untuk wall-art, pelatihan komputer dalam program ini juga sebagai dukungan untuk anak anak agar kelak tidak mengalami kesulitan dalam pengoperasian teknologi digital. Untuk itu kegiatan ini juga disesuaikan dengan usia dan kemampuan siswa.

Peneliti memilih untuk memperkenalkan aplikasi Ms. Word dan Canva kepada para siswa karena dianggap aplikasi tersebut sangat sederhana dan sering dibutuhkan penggunaannya. Meskipun demikian, siswa tidak harus mempelajari seluruh tools dalam aplikasi tersebut. Ketika belajar Ms. Word, siswa diintruksikan untuk membuat tabel jadwal harian sehingga hanya memerlukan menu home dan insert. Untuk penggunaan canva, peneliti hanya memperkenalkan terkait adanya fitur desain gratis yang memudahkan kita dalam membuat desain baru sesuai yang kita inginkan.

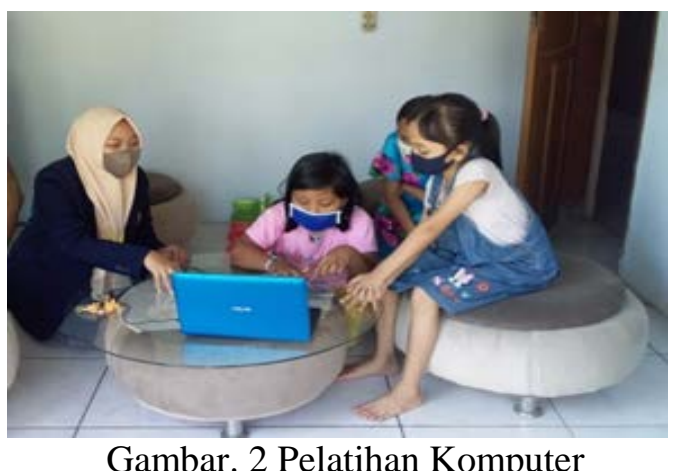

\section{Menceritakan Cita - Cita}

Pada kegiatan ini anak diberi motivasi terkait harapan masa depan yang cerah terlebih dahulu. Setelah itu anak dibebaskan berimajinasi terkait pilihannya dalam memilih sebuah cita cita. Peneliti memfasilitasi siswa dengan buku gambar dan pensil warna agar setiap siswa dapat mengekspresikan cita - citanya. Selain itu siswa juga diutus mendeskripsikan terkait tokoh yang dia cita - citakan kemudian menceritakannya dihadapan teman - temannya. Hal ini diharapkan dapat meningkatkan rasa percaya diri dan optimisme dalam diri setiap anak sehingga selalu memiliki semangat dalam memperjuangkan masa depan yang cerah dalam hidupnya.

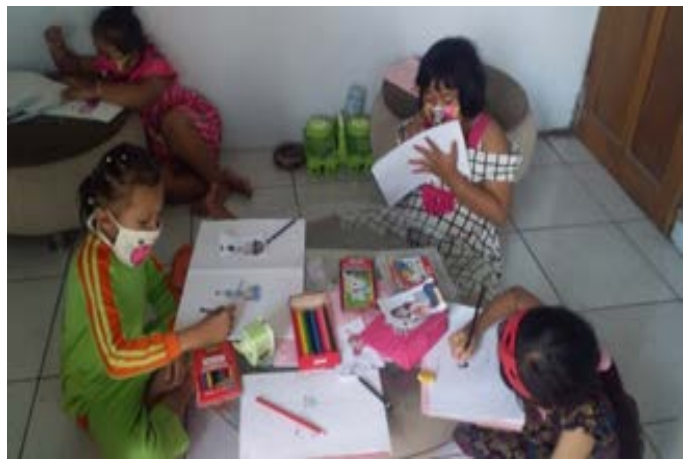

Gambar. 3 Menggambar Cita - Cita 


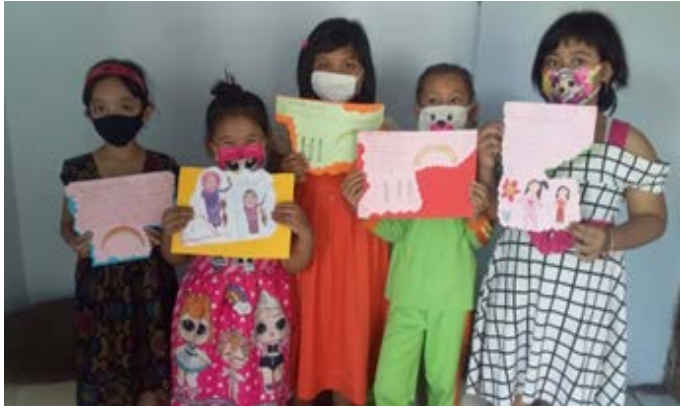

Gambar. 4 Menggambar Cita - Cita

\section{Membuat Puisi Bebas}

Pada kegiatan ini anak - anak diutus membuat karya tulis bebas berupa puisi. Tujuan dari dilakukannya kegiatan ini yaitu untuk melatih motorik halus anak serta mengajarkannya mengeksplorasi perasaannya dalam hal - hal positif. Anak juga diutus maju dan membacakan puisinya didepan teman temannya untuk melatih rasa percaya dirinya.

\section{Membuat Karya Seni Origami}

Pada kegiatan ini anak diajari membuat ketrampilan lipat dari ekrtas origami untuk melatih keterampilannya. Beberapa kali siswa diberi contoh kemudian dibebaskan dalam membuat karya sesuka hatinya dan harus menyelesaikan dalam waktu yang ditentukan yakni selama satu jam. Siswa dengan hasil origami terbanyak akan mendapatkan hadiah. Hal ini bertujuan agar setiap anak memiliki rasa tanggung jawab dalam menyelesaikan setiap pekerjaan serta membangun jiwa kompetitif antar teman dengan tetap menjaga sikap saling menghargai.

\section{Merangkai Wall-Art}

Kegiatan ini merupakan akhir atau tahap penyelesaian dari keseluruhan program yakni penyusunan wall-art schedule magazine dari karya karya yang telah dihasilkan. Setiap siswa diberi apresiasi terkait apa yang telah diusahakannya.

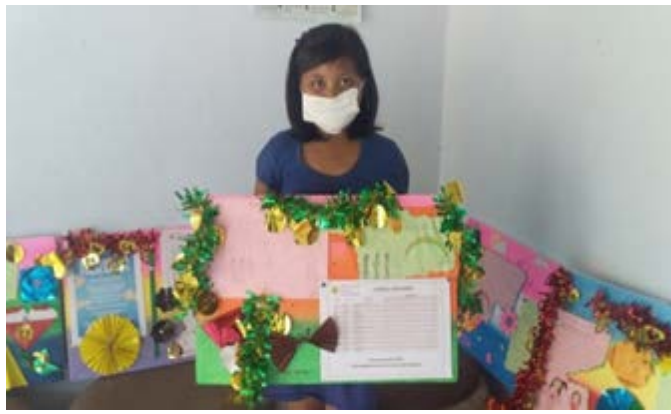

Gambar. 7 Hasil Akhir Wall-Art

\section{Evaluasi}

Penutupan program dilakukan dengan kegiatan evaluasi melalui perubahan kebiasaan dan respon sasaran selama kegiatan KKN Back To Village berlangsung.

\section{SIMPULAN}

Dampak pandemic Covid-19 sangat dirasakan dalam aspek pendidikan di Indonesia. Kegiatan belajar mengajar yang dilaksanakan secara online hingga saat ini menimbulkan berbagai keluhan. Tidak adanya inovasi pembelajaran mengakibatkan rasa bosan pada siswa sehingga tercipta pembelajaran yang tidak berkualitas.

Oleh karena itu KKN Back To Village menggagas program belajar dan berkarya untuk meningkatkan minat belajar anak terutama dalam hal pendidikan kecakapan hidup. Proses kegiatan ini berlangsung dalam lima tahap

Hal ini diterima dengan antusias oleh sasaran KKN yang merupakan anak SD kelas 1-3. Produk yang dihasilkan dari program ini yaitu WallArt Schedule Magazine.

\section{DAFTAR PUSTAKA}

Aji, S. H. R. 2020. Dampak Covid-19 Pada Pendidikan Indonesia; Sekolah, Keterampilan, dan Proses Pembelajaran. Jurnal 
Della Kharisma Putri, dkk. Inisiasi Pendampingan Pendidikan Kecakapan Hidup...

Sosial \& Budaya Syar-i. 7(5): $395-402$.

Direktoral Jenderal Pencegahan dan Pengendalian Penyakit. 2020. Pedoman Pencegahan dan Pengendalian Coronavirus Disease (Covid-19). Jakarta: Kementerian Kesehatan Republik Indonesia.

https://mojokertokab.go.id

https://prodeskel.binapemdes.kemendag ri.go.id/mpublik/

Hayat, N. 2012. Origami Bantu Pekembangan Otak Anak. https://www.google.com/amp/s /kalbar.antaranews.com/amp/b erita/307760/origami-bantuperkembangan-otak-anak. [Diakses pada: 10 Agustus 2020]

Roffiq, A., Qiram, I., Rubiono, G. 2017. Media Musik Dan Lagu Dalam Proses Pembelajaran. Jurnal Pendidikan Dasar Indonesia. $35-40$.

Setiani, $\quad$ F., $\quad$ Rasto. 2016. Mengembangkan Soft Skill Siswa Melalui Proses Pembelajaran. Jurnal Pendidikan Manajemen Perkantoran. 1(1): 160 - 166. 